\title{
Immediate Release Dosage Form
}

National Cancer Institute

\section{Source}

National Cancer Institute. Immediate Release Dosage Form. NCI Thesaurus. Code C42669

A solid, semi-solid, solution or suspension that is designed to release its active and/or inert ingredient(s) upon administration with no enhanced, delayed or extended release effect. 